\title{
Kinetics of Nitration of cis-1,4-Polybutadiene Rubber in Solution with Nitrogen Dioxide
}

\author{
I. Mladenov, G. Kostov, and V. RasheV \\ Chemical Technological Institute, Burgas, Bulgaria
}

(Received December 7, 1977)

\begin{abstract}
The kinetics of nitration of $c i s-1,4$-polybutadiene rubber dissolved in dichloroethane in the range of concentrations up to $2.2 \%$ was studied in a stirred cell. It was found that diffusion of nitrogen dioxide is not important and the reaction is of the first order with respect to both reactants. The overall second-order reaction rate constant was found to be about $1.1 \times 10^{-5} l /(\mathrm{gmol} \mathrm{sec})$ at $303 \mathrm{~K}$. The obtained value for the activation energy corresponds to kinetic regime. Based on these results a reaction mechanism is proposed.

KEY WORDS Kinetics / Nitration / Polybutadiene Rubber / Solution /

Kinetic Regime / Reaction Mechanism / Reaction Rate /
\end{abstract}

The nitration of polymers holds out new possibilities for changing and improving their qualities, and for obtaining many new products with valuable properties as well. In spite of a great number of investigations which have been made in that direction, ${ }^{1}$ there is very little information regarding the kinetics of elastomer-nitrating agent interaction. $^{1-3}$ This is due to the complexity of polymer conversions at which the functional composition and physical properties of macromolecules are simultaneously changed. Apart from that, for lack of a built-up and widely accepted theory and methods of investigation, it is difficult to establish the mechanism and kinetics of the nitration of elastomers.

This work is an attempt to apply the theory of gas absorption accompanied by chemical reaction to discern the type and kinetic mechanism of interaction of a solution of $c i s-1,4$-polybutadiene rubber in 1,2-dichloroethane(DCE) with nitrogen dioxide.

\section{EXPERIMENTAL}

\section{Materials}

For this purpose, an elastomer type SKD-2* was used. It was purified by a double precipitation with methanol from a $2-\%$ solution in DCE.

* SKD-2 is a commercial Russian butadiene rubber zontaining $96-98 \%$ cis-1,4-structure.
Pure nitrogen dioxide was obtained by thermal decomposition of reagent grade $\mathrm{Pb}\left(\mathrm{NO}_{3}\right)_{2}$, followed by further purification of the gas consisting of a reiterated crystallization of its dimer form at $-20^{\circ} \mathrm{C}$.

\section{Procedure}

Experiments were carried out in a $6.6-\mathrm{cm}$ i.d. glass stirred cell with an effective interfacial area of $31.8 \mathrm{~cm}^{2}$ which was similar to that used by Dankwerts and Sharma. ${ }^{4}$ The stirred cell was provided with a glass jacket where constanttemperature water circulated from a thermostat. A glass stirrer with four flat blades was used. The liquid level in the cell was adjusted so that the stirrer just dipped into the liquid. The speed of agitation could be kept constant in the range of 40 to $120 \mathrm{rpm}$.

Figure 1 shows the experimental set up. It was possible to operate continuously (contour I in Figure 1) or in a batch manner (contour II in the same figure) with respect to the gas, i.e., without discharge of the gas.

In the experiments the gas line and the stirred cell were first purged with nitrogen dioxide. After that , a known amount $(100-200 \mathrm{ml})$ of the rubber solution of known concentration was introduced into the cell. On rotating the stirrer, nitrogen dioxide saturated with DCE at the reaction temperature was passed into the cell and its flow rate 


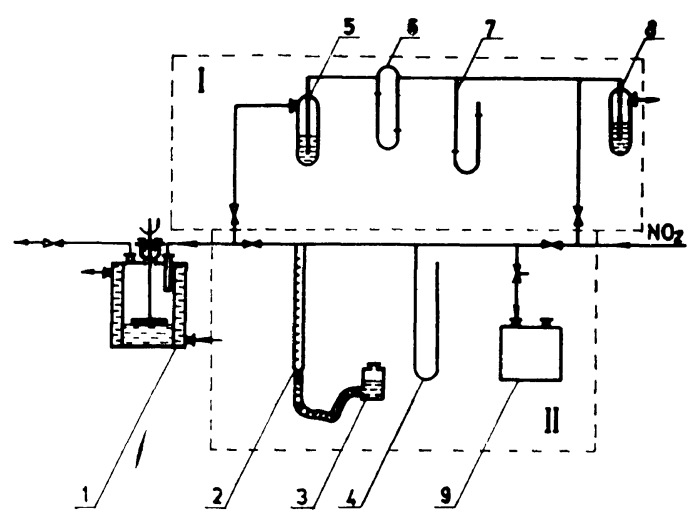

Figure 1. Experimental set-up: 1, stirred cell; 2, burette; 3 , vessel with mercury; 4, vacuum gage; 5 , bubbler for saturation with DCE, 6 , capillary flowmeter; 7, manometer; 8 , constant pressure device; 9, vacuum pump.

measured by flowmeter 6 (operated continuously). When operated without discharge of gas, the amount of nitrogen dioxide consumed during the reaction was read from the change in its volume in the apparatus with time. The latter manner proved to be very convenient, especially when operating under reduced pressure.

After the reaction time had elapsed, the flow of nitrogen dioxide was stopped. The reaction mixture was taken out of the stirred cell, bubbled with nitrogen, and the polymer was precipitated with methanol. The solid part was filtered off, and dried under vacuum to constant weight. Then, the product was analyzed for nitrogen content by Duma's method. ${ }^{5}$ Parallel determinations showed that the amount of combined nitrogen estimated from volume measurements (when operated without outlet of the gas) agreed fairly well with the results obtained from chemical analysis.

From this, the rate of absorption of nitrogen dioxide at a given speed of the stirrer was obtained and the enhancement factor of the reaction calculated.

The specific rate of absorption $R$ was determined according to the formula

$$
R=\frac{V\left(\left[\mathrm{~B}_{\mathrm{f}}\right]-\left[\mathrm{B}_{\mathrm{H}}\right]\right)}{z F t}, \mathrm{gmol} / \mathrm{cm}^{2} \mathrm{sec}
$$

where,

$$
V \text {, volume of solution, } \mathrm{m} l \text {; }
$$

$\left[\mathrm{B}_{1}\right]$, $\left[\mathrm{B}_{\mathrm{f}}\right]$, initial and final concentrations of nitroproduct in the reaction mixture resp., $\mathrm{gmol} / \mathrm{cm}^{3}$;

$F$, interfacial area, $\mathrm{cm}^{2}$;

$z$, stoichiometric factor of the reaction;

$t$, reaction time, sec.

and the enhancement factor $E$ from eq 2

$$
E=\frac{R}{k_{\mathrm{L}}\left[\mathrm{A}^{*}\right]},
$$

where,

$k_{\mathrm{L}}$, physical mass transfer coefficient, $\mathrm{cm} / \mathrm{sec}$;

[A*], solubility of nitrogen dioxide in the solution, $\mathrm{gmol} / \mathrm{cm}^{3}$.

To determine the concentration of nitro-product [B] the degree of conversion was calculated on the basis of the mechanism proposed for the nitration of some polymers. ${ }^{2,3,6}$ According to this mechanism, the main products were nitro-nitrites and di-nitro compounds.

\section{RESULTS AND DISCUSSION}

Values of $k_{\mathrm{L}}$ were obtained by measurements of volumetric rate of absorption of the pure $\mathrm{NO}_{2}$ into DCE at various stirring speeds as a function of time. A correction for the effect of viscosity and diffusivity was then made. ${ }^{7}$ Solubility [A*] was determined by saturating DCE with $\mathrm{NO}_{2}$ at different temperatures and analyzing the dissolved gas with back titration. ${ }^{9}$ The solubility of nitrogen dioxide in the rubber solution was taken to be the same as in DCE. This is unlikely to result in any significant error since the solutions were relatively dilute. Table I shows solubility data.

Since the solubility of $\mathrm{NO}_{2}$ in DCE is high, in order to eliminate gas-film resistance, pure gas without diluent was used in all experiments. To avoid any significant increase in the viscosity of solution and precipitation of insoluble nitroproduct, the concentrations of rubber solution were set in the range $0.037-0.407 \mathrm{gmol} / l(0.2-2.2 \%)$ and the maximum reaction time was not greater than $10 \mathrm{~min}$.

The results from the first set of experiments served as a basis for establishing the regime which the reaction followed. It has been found that the specific rate of absorption was independent of the speed of stirring (i.e., of $k_{\mathrm{L}}$ ). From Figure 2 it is seen that the specific rate of absorption in- 
Nitration of Polybutadiene Rubber

Table I. Solubility of $\mathrm{NO}_{2}$ in DCE at $760 \mathrm{~mm}$ mercury

\begin{tabular}{|c|c|c|c|c|c|c|c|c|}
\hline $\begin{array}{l}\text { Temperature, }{ }^{\circ} \mathrm{C} \\
\text { Dissolved }\end{array}$ & 15.0 & 20.0 & 25.0 & 31.4 & 33.0 & 40.0 & 50.0 & 55.0 \\
\hline $\begin{array}{l}\mathrm{NO}_{2} \times 10^{3}, \\
\mathrm{gmol} / \mathrm{cm}^{3}\end{array}$ & 5.24 & 4.19 & 3.24 & 2.52 & 2.27 & 1.63 & 1.12 & 0.98 \\
\hline
\end{tabular}

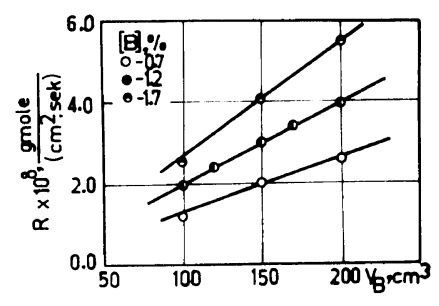

Figure 2. Specific rate of absorption $R$ against volume of rubber solution $V_{\mathrm{B}}$; partial pressure of nitrogen dioxide $p_{\mathrm{NO}_{2}}=0.872 \mathrm{~atm}$.

creased linearly with the volume of the rubber solution. In accordance with the theory of gas absorption accompanied by chemical reaction, this suggests that the reaction conforms to kinetic control. This was confirmed by the values of the enhancement factor $E$ which remained less than unity, i.e., the conditions for a kinetically controlled slow reaction were fulfilled. This means that the rate of transfer of nitrogen dioxide to the liquid phase is much faster than the rate of the chemical reaction. Hence the liquid phase is saturated with $\mathrm{NO}_{2}$ at any given moment, the diffusional factors are unimportant and the rate of formation of nitro-products is determined by the kinetics of the homogeneous chemical reaction. In such a case, the following equation holds

$$
R^{\prime}=k_{m n}\left[\mathrm{~A}^{*}\right]^{m}[\mathrm{~B}]^{n} / V, \quad \mathrm{gmol} / \mathrm{cm}^{3} \mathrm{sec}
$$

where

$R^{\prime}$, volumetric rate of absorption, gmol $/ \mathrm{sec}$;

$k_{m n}$, reaction rate constant which is of $m$-order with respect to the gas and of $n$-order with respect to the elastomer, $\mathrm{cm}^{3} /\left(\mathrm{gmol}^{m+n-1}\right.$ $\mathrm{sec})$.

From eq 3 it is seen that to determine the value of $k_{m n}$, the order with respect to the nitrogen dioxide

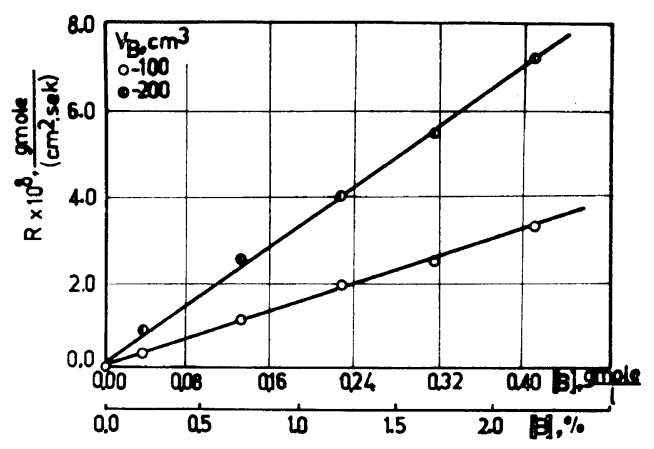

Figure 3. Specific rate of absorption $R$ against concentration of rubber solution $[\mathrm{B}] ; p_{\mathrm{NO}_{2}}=0.872 \mathrm{~atm}$.

and to the elastomer is necessary. That is why in the next runs the concentrations of the two reactants were changed. Figure 3 is a plot of $R$ against the elastomer concentration in solution [B] at constant $\left[\mathrm{A}^{*}\right]$. The linear dependence of $R$ on [B] indicates that the reaction is of the first order with respect to polybutadiene rubber. Figure 4 is a plot of $R v s$. [A*] at constant [B]. It follows also that the reaction is of the first order with respect to nitrogen dioxide. Now, eq 3 makes possible calculation of values of the reaction rate constant. $k_{2}$ was found to be $1.1 \times 10^{-2} \mathrm{~cm}^{3} /$ (gmol sec) at $303 \mathrm{~K}$.

In order to determine the activation energy of the reaction from Arrhenius equation, experiments at different temperatures were carried out. The results are shown in Table II.

The activation energy was found to be -10.4 $\mathrm{kcal} / \mathrm{gmol}$ for $288-303 \mathrm{~K}$ and $14.2 \mathrm{kcal} / \mathrm{gmol}$ for $303-319 \mathrm{~K}$, which corresponds to the kinetic regime $^{9}$ and to the nitration as an addition reaction.

The change in the energy might be explained by

Table II. Rate constants and activation energy of the reaction

$\begin{array}{lccccccc}\text { Temperature, } \mathrm{K} & 288 & 293 & 298 & 303 & 309 & 315 & 319 \\ \begin{array}{l}\text { Rate constant } k_{2} \times 10^{2}, \\ \mathrm{~cm}^{3} /(\mathrm{gmol} \mathrm{sec})\end{array} & 2.6 & 2.0 & 1.6 & 1.1 & 2.1 & 2.8 & 3.9 \\ \text { Activation energy, kcal/gmol } & & & & & & & \\ \end{array}$


Table III. Extinction ratios of the nitrated polybutadiene

\begin{tabular}{lrrrrrrr}
\hline Temperature, ${ }^{\circ} \mathrm{C}$ & 15 & 20 & 25 & 30 & 36 & 42 & 46 \\
$E_{\mathrm{C}-\mathrm{N}} / E_{\mathrm{C}-\mathrm{ON}}$ & 0.45 & 0.62 & 0.80 & 0.86 & 2.24 & 2.57 & 4.43 \\
\hline
\end{tabular}

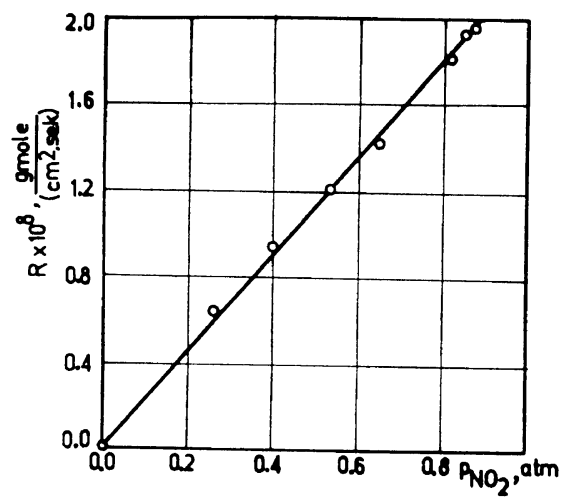

Figure 4. Specific rate of absorption $R$ against partial pressure of nitrogen dioxide $p_{\mathrm{NO}_{2}}$ : concentration of elastomer, $1.2 \%$; volume of solution, $100 \mathrm{~cm}^{3}$.

the mechanism of nitration in the used solvent and temperature range.

Royo, et al., ${ }^{6}$ established that when chlorination or nitration of polybutadiene are conducted in solvents with high dielectric constants (tetrahydrofuran) up to a border-line concentration, cross-linking reactions are suppressed, and only addition and isomerization reactions may occur. The authors indicated that in the nitrated polybutadiene the absorption bands at 1635 and 1548 $\mathrm{cm}^{-1}$ are assigned to $-\mathrm{O}-\mathrm{N}=\mathrm{O}$ group and $-\mathrm{C}-$ $\mathrm{NO}_{2}$ group, respectively.

In the IR spectra of the reaction products obtained in this investigation, the absorption peaks for nitroso $(-\mathrm{C}-\mathrm{NO})$ and nitrite-ester $(-\mathrm{C}-$ ONO) groups were not established. As for the solvent we used, DCE possesses a higher dielectric constant than tetrahydrofuran (10.2 against 7.4, resp.), the concentrations of rubber solutions are under border-line and the reaction time does not exceed $10 \mathrm{~min}$, so presumably all of the conditions necessary for the addition and isomerization reaction are fulfilled.

On the other hand, when $\mathrm{N}_{2} \mathrm{O}_{4}$ is used as the nitrating agent, the reactions proceed according to an ionic mechanism. As the equilibrium of the reaction (eq 4) goes to the left when the tem-

$$
\mathrm{N}_{2} \mathrm{O}_{4} \rightleftarrows 2 \mathrm{NO}_{2}
$$

perature is lowered, obviously at low tempera- tures of nitration the ionic mechanism of interaction will prevail. Besides the temperature, the type of solvent will also influence the mechanism of nitration. The use of a solvent with a high dielectric constant, might benefit the ionic mechanism. Because of this, we observed the prevalence of ionic mechanism even at temperatures higher than room temperature (up to $303 \mathrm{~K}$ ) while Royo, et al., ${ }^{6}$ stress that the reaction of nitrogen dioxide with polybutadiene at this temperature is predominantly of a radical character. Where we noticed an ionic reaction, the interaction in the polymer chain results mainly in nitrate-ester $\left(-\mathrm{ONO}_{2}\right)$ groups, while the radical mechanism results in a nitro $\left(-\mathrm{NO}_{2}\right)$ group. Hence, the ratio between $\mathrm{C}-\mathrm{N}$ and $\mathrm{C}-\mathrm{ON}$ groups in the reaction products may serve as a basis for establishing the mechanism of nitration.

Table III shows the ratios of extinction of characteristic absorptions of $\mathrm{C}-\mathrm{N}\left(\right.$ at $1350 \mathrm{~cm}^{-1}$ ) and $\mathrm{C}-\mathrm{ON}$ (at $1630 \mathrm{~cm}^{-1}$ ) groups for the reaction products obtained at different temperatures of nitration. It may be seen that with an increase of the reaction temperature, the proportion of nitrogroups also increases. The reaction appears to be complex since it involves different products of the ionic and free-radical mechanisms. At least, in the low temperature range $\left(15-30^{\circ} \mathrm{C}\right)$ the reaction may follow an ionic mechanism. The overall reaction rate decreases, while the temperature increases and the energy of activation is negative. At high temperatures $\left(30-46^{\circ} \mathrm{C}\right)$ the equilibrium in eq 4 goes to the right, the free-radical mechanism predominates and the reaction has a positive temperature coefficient.

\section{REFERENCES}

1. I. Mladenov, D. Sc. Thesis, Chemistry Technology Institute Sofia, 1975.

2. H. H. G. Jellinek and J. Toyoshima, J. Polym. Sci., Part A-1, 5, 3214 (1967).

3. H. H. G. Jellinek, F. Flaysman, and F. G. Kryman, J. Appl. Polym. Sci., 13, 107 (1969).

4. M. M. Sharma and P. V. Danckwerts, Chem. Eng. Sci., 19, 991 (1964). 
5. B. Stojanove-Ivanova, Short Course of Organic Analysis, Nauka i Izkustvo, Sofia, 1967, p 191.

6. J. Royo, L. Gonzales, L. Ibarra, and M. Barbero, Makromol. Chem., 168, 41 (1973).

7. A. S. Jhaveri and M. M. Sharma, Chem. Eng. Sci., 22, 1 (1967).
8. G. Charlo, "Methods of Analytical Chemistry, Russian Translation," Khimia, Moscow, 1965, p 551.

9. D. A. Frank-Kamenetzkii, "Diffusion and Heat Transfer in Chemical Kinetics," Nauka, Moscow, 1951, p 124. 